surgery in the first place because of the presence of severe MAC. Does this operation, as described by Chang and colleagues, ${ }^{1}$ offer a better chance for those patients with severe MAC who otherwise would face a risky reconstructive procedure? One suspects that it might, although even with this technique there are challenges, such as ensuring that sutures can be sewn around the calcified annulus and the adjacent left atrial tissue or avoiding damage to a dominant circumflex artery if present in the atrioventricular grove. Their operation could be simplified somewhat by removing the entire anterior mitral leaflet while preserving the posterior leaflet attachments to the chordae. Their follow-up is relatively short (less than a year), and it remains to be seen whether thrombosis occurs in the "dead space" inside the graft between the native mitral annulus and the prosthetic valve. No doubt imminent advances in transcatheter based valve implantation technologies may facilitate correction of mitral valve disease in patients with severe MAC. Until such time, however, the technique described by Chang and colleagues ${ }^{1}$ deserves consideration by any surgeon performing mitral valve surgery, especially in the face of severe MAC.

\section{References}

1. Chang J-P, Lo C-M, Wu C-C, Fu M. Valved-conduit-on-valve implantation for physiologic total chordal preservation in rheumatic mitral valvulopathy. J Thorac Cardiovasc Surg. 2015;149:1453-5.

2. Sung SC, Chang YH, Lee HD, Woo JS. A novel technique of supra-annular mitral valve replacement. Ann Thorac Surg. 2008;86:1033-5.

3. Carpentier A, Pellerin M, Fuzellier J, Relland J. Extensive calcification of the mitral valve anulus: pathology and surgical management. J Thorac Cardiovasc Surg. 1996;111:718-29; discussion 729-30.

4. Feindel CM, Tufail Z, David TE, Ivanov J, Armstrong S. Mitral valve surgery in patients with extensive calcification of the mitral annulus. J Thorac Cardiovasc Surg. 2003;126:777-82.

5. Papadopoulos N, Dietrich M, Christodoulou T, Moritz A, Doss M. Midterm survival after decalcification of the mitral annulus. Ann Thorac Surg. 2009;878:1143-7.

\title{
Fluorescence-guided placement of an endoaortic balloon occlusion device for totally endoscopic robotic mitral valve repair
}

\author{
David W. Yaffee, MD, Didier F. Loulmet, MD, Ans G. Fakiha, MD, and Eugene A. Grossi, MD, New York, NY
}

See related commentary pages $1458-9$.

Totally endoscopic robotic mitral valve repair (TERMR) is performed with 4 robotic port sites and a single $2-$ to $3-\mathrm{cm}$ access incision used to pass instruments, suction, sutures and annuloplasty devices. An endoaortic balloon occlusion device (endoballoon) replaces both the external aortic crossclamp and the aortic root line during TERMR. Used in approximately 4000 patients annually, this technique has the advantage of eliminating the clutter of a physical crossclamp in the surgical field, as well as the additional incision it requires, and of avoiding the need to puncture the

\footnotetext{
From the Department of Cardiothoracic Surgery, NYU Langone Medical Center, New York, NY

Disclosures: Didier Loulmet reports consulting fees from Medtronic. Eugene Grossi has intellectual property with Edwards Lifesciences for which he receives royalties. All other authors have nothing to disclose with regard to commercial support.

Received for publication Dec 18, 2014; accepted for publication Jan 2, 2015; available ahead of print Jan 29, 2015.

Address for reprints: Eugene A. Grossi, MD, 530 First Ave, Suite 9V, New York, NY 10016 (E-mail: Eugene.grossi@nyumc.org).

J Thorac Cardiovasc Surg 2015;149:1456-8

$0022-5223 / \$ 36.00$

Copyright (c) 2015 by The American Association for Thoracic Surgery

http://dx.doi.org/10.1016/j.jtcvs.2015.01.005
}

ascending aorta for cardioplegia, venting, and deairing, simplifying the totally endoscopic procedure. Determining the position of the endoballoon without radiographic fluoroscopy requires the use of narrow transesophageal echocardiographic views (Figure 1, $A$ ) and differential upper extremity pressure monitoring. Once the left atrium has been opened to expose the mitral valve the echocardiographic window is lost (Figure 1, B), making it difficult to confirm or reposition the endoballoon under echocardiographic guidance. We sought to determine whether the endoballoon filled with the fluorescent dye indocyanine green (ICG) could be directly visualized with the fluoroscopic feature of the robotic endoscope, and whether this would facilitate placement and positioning of the endoballoon.

\section{TECHNIQUE}

Pericardiotomy is performed to the superior pericardial reflection with stay suture placement to provide visualization of the aortic root and ascending aorta. The endoballoon (IntraClude Intra-Aortic Occlusion Device; Edwards Lifesciences, Irvine, Calif) is inserted through a side port of the femoral arterial cannula and advanced into the ascending aorta over a guidewire under echocardiographic guidance. When aortic occlusion is desired, the balloon is inflated with a $0.03 \%$ solution of ICG (IC-Green; Akorn Inc, Lake Forest, Ill) in 5\% albumin to a pressure of 250 to $350 \mathrm{~mm} \mathrm{Hg}$. The ICG-albumin 


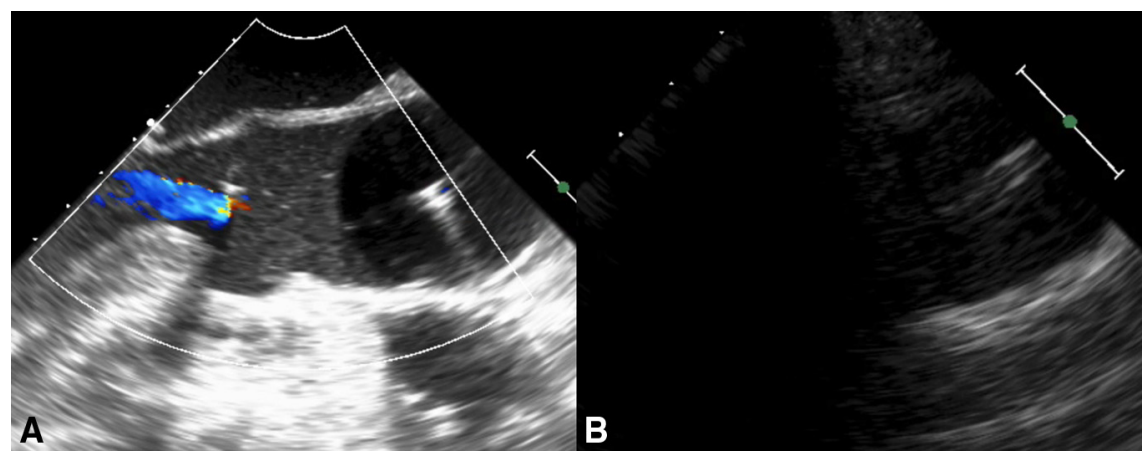

FIGURE 1. A, Transesophageal echocardiographic window of the endoballoon inflated in appropriate position in the ascending aorta. B, Once the left atrium is opened and evacuated, the echocardiographic window is lost, making it difficult to confirm or reposition the endoballoon under echocardiographic guidance.

solution is contained within the endoballoon; there is no direct administration to the patient. Because ICG is weakly fluorescent natively but strongly fluorescent when protein bound, albumin must be added for this technique, unlike in other applications when the dye is being used intravascularly. The protein-bound ICG is excited by a near-infrared laser in the robotic endoscope (da Vinci Xi; Intuitive Surgical, Inc, Sunnyvale, Calif) and fluoresces, allowing it to be clearly visualized as a green band through the aortic wall with the robotic fluoroscopic camera (Figure 2).

TERMR with an ICG-inflated endoballoon was performed in 30 cases. Once the left atrium was opened and the echocardiographic window was lost (Figure 1), it became difficult to localize the endoballoon accurately under direct vision in the visible spectrum (Figure 2, A). With the robotic endoscope, however, the fluorescent endoballoon was easily visualized (Figure 2, $B$ ) allowing the precise evaluation of balloon positioning in all cases. When necessary, the endoballoon was quickly and accurately repositioned under fluoroscopic vision without the use of echocardiographic guidance.

\section{DISCUSSION}

Inflation of the endoballoon with the fluorescent dye ICG during TERMR allows for fast and accurate positioning and continuous real-time monitoring of endoballoon location with the fluorescent camera integrated into the da Vinci Xi system. Even when the left atrium has been opened and the echocardiographic window of the aortic root and ascending aorta is lost, the endoballoon can be easily repositioned or replaced. Fluoroscopy is never used.

ICG was developed by Kodak as a photographic dye before being identified for clinical use in the late 1950s. ${ }^{1}$ ICG absorbs light between 600 and $900 \mathrm{~nm}$ and has a wide fluorescent emission spectrum of 750 to 950 $\mathrm{nm}$. It binds tightly to plasma proteins when administered systemically, confining it to the vascular system before its excretion in bile, with a half-life of 150 to 180 seconds. ICG was first used in medicine for determining cardiac output and hepatic function and later in surgery with uses ranging from retinal angiography to sentinel lymphography to determination of coronary graft patency. ${ }^{2}$ More recently, ICG has been used in robotic surgery to differentiate normal renal parenchyma from tumor during partial nephrectomy ${ }^{3}$ and to determine surgical planes during pulmonary segmentectomy. ${ }^{4}$ Unlike in these cases, where the ICG is administered systemically, the ICG used in the endoballoon is isolated from the patient, minimizing the risk of rare adverse reactions to the dye. ${ }^{5}$

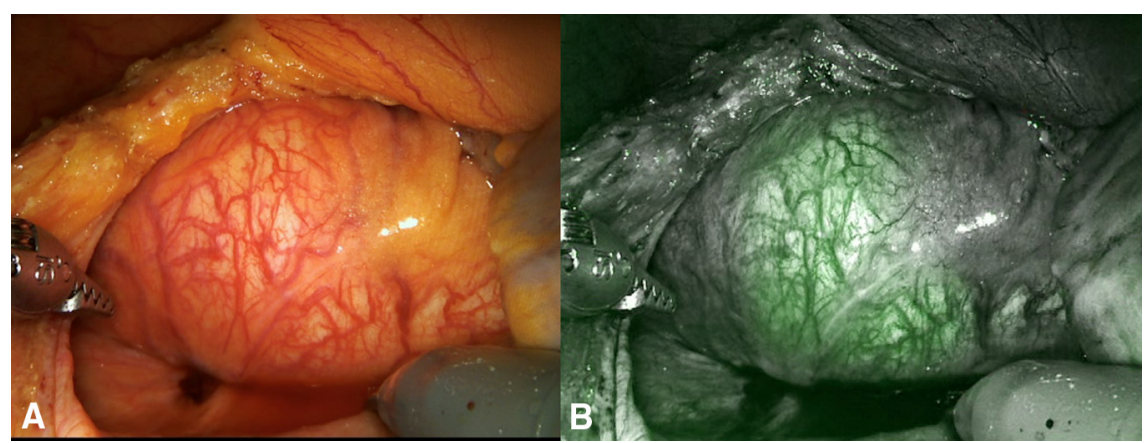

FIGURE 2. A, Identification of the position of the endoballoon is difficult when the ascending aorta is viewed through the robotic endoscope in the visible spectrum. B, When viewed with the fluorescent feature of the endoscope, however, the endoballoon is clearly visible as a green band transilluminating the wall of the aorta, greatly simplifying the accurate placement and repositioning of the endoballoon. 
ICG inflation of the endoballoon in TERMR allows the accurate placement of the endoballoon and continuous real-time visualization and monitoring of its position. When the echocardiographic window is lost, direct visualization of the fluorescent endoballoon allows verification of the location and quick and easy repositioning of the endoballoon during the mitral repair, without the need for radiographic fluoroscopy. Because the ICG is not administered directly to the patient, risk is minimal. This novel technique both simplifies the use and improves the safety of the aortic endoballoon for TERMR.

\section{References}

1. Burchell HB. Assessment of clinical value: symposium on diagnostic applications of indicator-dilution technics. Proc Staff Meet Mayo Clin. 1957;32:551-3.

2. Alander JT, Kaartinen I, Laakso A, Pätilä T, Spillmann T, Tuchin VV, et al. A re view of indocyanine green fluorescent imaging in surgery. Int J Biomed Imaging. 2012;2012:940585

3. Harke N, Schoen G, Schiefelbein F, Heinrich E. Selective clamping under the usage of near-infrared fluorescence imaging with indocyanine green in robotassisted partial nephrectomy: a single-surgeon matched-pair study. World J Urol. 2014:32:1259-65.

4. Pardolesi A, Veronesi G, Solli P, Spaggiari L. Use of indocyanine green to facilitate intersegmental plane identification during robotic anatomic segmentectomy. $J$ Thorac Cardiovasc Surg. 2014;148:737-8.

5. Hope-Ross M, Yannuzzi LA, Gragoudas ES, Guyer DR, Slakter JS, Sorenson JA, et al. Adverse reactions due to indocyanine green. Ophthalmology. 1994;101:529-33.

\section{EDITORIAL COMMENTARY}

\section{"Glow in the dark" intraoperative imaging: Expanding the capabilities of robotic technology}

Andrew B. Goldstone, MD, and Y. Joseph Woo, MD

See related article on pages 1456-8.

In this issue of the Journal, Yaffee and colleagues ${ }^{1}$ from New York University describe a novel fluorophore-based approach for the precise placement of an endoaortic balloon occlusion device during totally endoscopic robotic mitral valve repair. In their series of 30 patients, the replacement of saline solution with indocyanine green and albumin facilitated indirect transaortic visualization of the endoaortic balloon. Their approach exploits the fluoroscopic imaging capabilities of the robotic endoscope to simplify endoaortic balloon positioning, and for this they should be congratulated. It is of interest, however, to know how this new visualization technique affected the conduct of the operation and its results. Did operative times shorten? Or, conversely,

From the Department of Cardiothoracic Surgery, Stanford University School of Medicine, Stanford, Calif.

Disclosures: Authors have nothing to disclose with regard to commercial support.

Received for publication Jan 26, 2015; accepted for publication Jan 28, 2015; available ahead of print March 7, 2015.

Address for reprints: Y. Joseph Woo, MD, Department of Cardiothoracic Surgery, Stanford University, Falk Building CV-235, 300 Pasteur Dr, Stanford, CA 94305-5407 (E-mail: joswoo@stanford.edu).

J Thorac Cardiovasc Surg 2015;149:1458-9

$0022-5223 / \$ 36.00$

Copyright (c) 2015 by The American Association for Thoracic Surgery

http://dx.doi.org/10.1016/j.jtcvs.2015.01.073 does the ability to see the true position of the balloon lead to more, perhaps unnecessary, manipulations of the balloon within the aorta?

Advancements in imaging, surgical

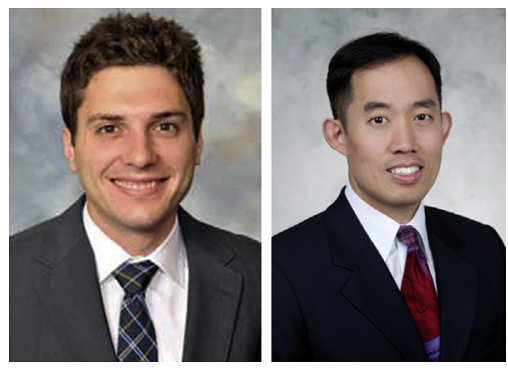
instrumentation, and robotic technology have enabled surgeons to perform complex cardiac surgical procedures through small incisions, often eliminating the need for sternotomy or cardiopulmonary bypass. The endoaortic balloon permits ascending aortic occlusion, cardioplegia delivery, and root venting, while simultaneously minimizes clutter in the surgical field. The balloon is initially inflated under echocardiographic guidance. Because the open heart compromises the echocardiographic window, surgeons must rely on concurrence between bilateral upper extremity arterial pressures for detection of balloon migration during surgery. Concerns of an increased risk of adverse vascular events (embolization, dissection, stroke, and lower extremity ischemia) limit widespread use of the endoballoon. Yet, increased experience with the device reliably decreases complication rates. $^{2,3}$ While a determination of whether the added visualization of the endoballoon will further reduce adverse vascular events is premature, this series by Yaffee and colleagues ${ }^{1}$ provides proof-of-concept data for a 